\title{
AS CONCEPÇÕES DE LEITURA PROPOSTAS NOS CADERNOS FORMATIVOS DO PACTO NACIONAL PELA ALFABETIZAÇÃO NA IDADE CERTA
}

\author{
READING CONCEPTIONS PROPOSED IN THE TRAINING INSTRUMENTS OF \\ THE NATIONAL PACT FOR LITERACY IN THE RIGHT AGE
}

Celina Loose

Mestrado em Educação e Linguagens (UFES).

Professora e Coordenadora Pedagógica. celinaloose27@yahoo.com.br

\begin{abstract}
Resumo
O estudo analisa os documentos usados na formação de professores do Pacto Nacional pela Alfabetização na Idade Certa (Pnaic) realizada em 2012, uma iniciativa resultante da parceria entre o governo federal, estados, municípios e universidades para que todas as crianças brasileiras sejam plenamente alfabetizadas até $03^{\circ}$ ano do Ensino Fundamental. A análise centra-se nos cadernos formativos de Língua Portuguesa usados pelos formadores e professores alfabetizadores do Pacto. O marco teórico baseou-se em Bakhtin (1999, 2003), que tem o diálogo e os sentidos como categorias marcantes nas relações verbais e nos enunciados. O estudo permitiu notar que a proposta para o trabalho de leitura orienta concepções com ênfase para usos sociais de leitura, em que o leitor é um sujeito ativo, que no encontro com o texto, recupera sentidos por meio de um conjunto de estratégias cognitivas para compreendê-lo.
\end{abstract}

Palavras-chave: alfabetização; concepções de leitura; produção de sentidos; Pnaic.

\begin{abstract}
:
The study analyses the documents used in teacher training of the National Pact for the Literacy of the Right Age (PNAIC, in Portuguese) in 2012, an initiative resultant of the partnership between the federal government, states, municipalities and universities so that all Brazilian children are fully literate by the 3rd year of Elementary School. The analysis focuses in the training books of the Portuguese Language, used by teachers and literacy teachers of the Pact. The theoretical framework was based on Bakhtin (1999, 2003), who considers the dialogue and the senses as remarkable categories in verbal relations and statements. The study showed the proposal for the reading work guides conceptions with an emphasis on social uses of reading, in which the reader is an active subject, who in the encounter with the text, recovers meanings through a set of cognitive strategies for comprehension of the text.
\end{abstract}

Keywords: literacy; reading conceptions; production of meanings; PNAIC. 


\section{Introdução}

O crescimento das tecnologias possibilita às crianças, desde os seus primeiros anos de vida, o acesso a uma diversidade textual, tanto no mundo da linguagem escrita quanto oral, o que impacta na sua formação. Para Carvalho (2012), a escola pode contribuir de muitas maneiras para formar indivíduos não somente alfabetizados, mas, também, participativos, ao Ihes possibilitar o mergulho no mundo da linguagem, partindo do saber, das vivências que os alunos trazem, acumulados informalmente, para o processo de ensino-aprendizagem na sala de aula.

Para Bakhtin (apud GONTIJO, 2002, p.1), "penetrar no mundo da linguagem [...] é penetrar no mundo da cultura, no interior das relações sociais existentes, porque a língua é material e instrumento de si mesma, produzida na interação social". Nessa perspectiva, ampliam-se as possibilidades de estabelecerem mais sentidos, além de criarem e recriarem a partir dessa comunicação interativa com o objeto e com o outro. Compreendemos que, nessa dinâmica, as crianças em formação passarão a estar mais bem acompanhadas, elevando sua capacidade de interagirem com a sociedade.

Essas várias formas de aproximar as crianças de outras potencialidades são requeridas do professor, por meio de um ensino formalizado e de qualidade. É da escola, no papel de instituição formadora, o compromisso com uma educação de qualidade. E dos municípios, estados e governo federal, a ação requer políticas públicas que deem condições de implementação de formações continuadas para os professores se aperfeiçoarem e assim, contribuírem para alavancar as metas já delineadas desde os anos 1990 e retomadas em discussões, posteriores, em 2000, no Fórum Mundial de Educação, como um compromisso global da "Educação para todos".

Embora tais metas, ainda não tenham sido plenamente operacionalizadas, nota-se nos últimos anos, por parte dos governos nacionais, uma mobilização para desenvolver ações formativas que pudessem assegurar o acesso e a qualidade da educação, especialmente em relação à leitura e à escrita no período de alfabetização, atuando, também, no sentido de promover a valorização dos profissionais.

No que diz respeito ao contexto brasileiro, em 2012, governos federal, estaduais e municipais, em parceria com as universidades públicas, firmaram o compromisso para promover a formação continuada do Pacto Nacional pela Alfabetização na Idade Certa (Pnaic). Realizada com os professores alfabetizadores, esta foi uma ação inédita do Ministério da Educação (MEC), mobilizando esforços e recursos para que todas as crianças brasileiras sejam plenamente alfabetizadas até os oito anos de idade.

Gontijo (2014) pontua que a alfabetização deve levar em conta, notadamente, os contextos sociais e históricos em que ocorre, para que, desse modo, seja concebida, igualmente, como prática social e cultural, porque se desenvolve em diferentes situações. Assim, a alfabetização configura um processo em que as crianças se reconhecem como protagonistas de suas histórias e de suas leituras, constituindo-se como sujeitos-leitores críticos e participativos.

A argumentação de Orlandi (2012) caminha no mesmo sentido, quando se trata do ensino da leitura, no qual, conforme o autor, é necessário considerar a importância das diversas linguagens com que a criança teve contato na fase que antecedeu sua entrada na escola. Afinal, o aluno não é uma folha em branco, não parte do zero, mas continua constituindo histórias de leituras e vivências no contato com a diversidade de linguagens com que se depara na escola e nos demais âmbitos da vida. 
Ainda que estar alfabetizado implique não apenas dominar leitura, escrita e compreensão de textos, estudos mostram que, ainda hoje, transcorridos 25 anos do debate inicial sobre tal temática, os conceitos de alfabetização adotados pelos programas retomam concepções que se restringem ao ensino de habilidades específicas, tomando o texto como pretexto para o ensino de unidades menores da língua (GONTIJO, 2014). Essa afirmação se confirma na análise que Costa (2017) fez de trabalhos que versavam sobre programas e projetos de formação de professores alfabetizadores e séries iniciais implementados de 2000 a 2016. Um deles é o Programa de Formação de Professores Alfabetizadores, sobre o qual Becalli (apud COSTA, 2017) aponta que as atividades destinadas à leitura e à escrita são, sobretudo, voltadas ao ensino de palavras. Algumas atividades enfatizavam o texto sem explorá-lo de forma que os alunos pudessem construir uma atitude responsiva, sendo tomado apenas como pretexto das relações entre o oral e o escrito. O mesmo foi observado quanto ao Projeto Trilhas, formação para professores das séries iniciais cuja ênfase, na dimensão leitura, estava nos textos literários, usados como pretextos para trabalhar o sistema de escrita da língua portuguesa e a estrutura textual (FERREIRA apud COSTA, 2017).

A partir das análises observamos que o ensino da leitura com tais práticas possibilita a entrada do texto em sala de aula, porém, sem ultrapassar o trabalho ainda um tanto mecanicista. Isso porque ele é tomado como objeto de interação, para articular um trabalho sobre a organização do texto. Entendemos que essa dinâmica até produz um sentido na vida dos estudantes em formação, mas o ensino da leitura focado em uma linha discursiva fica em segundo plano.

Diante do exposto, fica evidente a necessidade de se romper com esses velhos paradigmas que orientam o ensino da leitura e da escrita na fase da alfabetização. Assim, este estudo investigou as concepções de leitura propostas pelo Pnaic, uma vez que o programa foi de grande relevância para a formação continuada de professores alfabetizadores, constituindo-se em uma política educacional de abrangência nacional, instituída com a finalidade de melhorar a qualidade da educação. Para a análise, tomamos como referência a concepção dialógica proposta por Bakhtin, centrada na produção de sentidos, conforme apontado a seguir.

\section{Referencial teórico}

\section{Concepções de linguagem que orientam o processo de alfabetização}

Ao discorrer sobre os atos de ler e ser alfabetizado, Schwartz (2006, p. 3) apresenta a classificação de Zappone, que caracteriza quatro concepções de leitura. A concepção diagnóstica é marcada pelo "caráter detector e denunciador da situação desfavorável de leitura no Brasil". Centra-se na ideia de que o leitor participa da leitura com sua bagagem sociopolítica, cognitiva e cultural de mundo, construída a partir de seu contexto e das relações nele estabelecidas, não se reduzindo meramente à decodificação de um código escrito.

A finalidade da linguagem, na concepção diagnóstica, é a transformação do próprio mundo, a partir da tomada de consciência sobre este e sobre si, baseando-se na perspectiva freireana. Na escola, no entanto, sua operacionalização encontra barreiras, sobretudo, na concepção de leitura e formação dos professores, assim como nas condições em que o trabalho desses profissionais é realizado e nas concepções teóricas escolhidas (RANGEL apud SCHWARTZ, 2006). 
Na concepção cognitivo-processual, por sua vez, o foco da preocupação é entender "como se processa o aprendizado da leitura", esclarece Schwartz (2006, p. 3), partindo-se do entendimento de que esta constitui-se em um processo de interação entre leitor, texto e autor, perpassado por aspectos linguísticos e psicológicos.

A partir desta concepção, "ao ler, o leitor estaria recuperando o sentido do texto, bem como as intenções do autor, através das marcas" (SCHWARTZ, 2006, p. 3) que este deixou no que produziu. Tal abordagem, conforme a autora, tem sido criticada como romântica, por desconsiderar diferenças que funcionam como marcadores de exclusão e, por consequência, reproduzir a dinâmica assimétrica da realidade social.

Outra concepção de leitura que recebe críticas é a estruturalista, por deixar à margem questões históricas e os contextos de quem lê e em que se lê. Esta abordagem centra-se nos fatores de natureza linguística, entendendo que a decodificação é o que garante "a eficácia da leitura, como se fosse possível ao autor controlar todos os sentidos que o leitor possa produzir nos momentos da leitura", posicionando este como "mero reprodutor de ideias", portanto (SCHWARTZ, 2006, p. 5).

As abordagens até aqui destacadas também estão presentes em Geraldi (2004, p. 41), o qual descreve que a linguagem pode ser vista: a) como expressão do pensamento, o que dá a entender que quem não consegue usá-la não pensa - nesta concepção, o foco é o autor do texto; b) como instrumento de comunicação, em que a língua é o código com o qual se envia uma mensagem a alguém - aqui, a ênfase no texto continua, restringindo-se ao que nele está escrito; c) finalmente, "como um lugar de interação humana", extrapolando a mera transmissão de mensagens e possibilitando compromissos e vínculos que somente existem quando ela é ocorre.

O foco da última abordagem é a interação autor-texto-leitor, consistindo em uma forma de processamento textual em que o leitor é capaz de interagir com o texto a partir das pistas deixadas pelo autor. O texto é tido como lugar de interação e o momento da leitura abarca elementos implícitos e explícitos, produzindo sentido para o texto, de modo que o leitor alcança uma compreensão leitora.

$\mathrm{Na}$ quarta concepção listada por Zappone (apud SCHWARTZ, 2006), o ensino da leitura é concebido em uma linha discursiva, tendo como foco o leitor-autor-texto, portanto, tomando como ponto de partida o leitor. O processo de produção de sentidos se constitui no momento em que este chega ao texto, no qual já existe um leitor inscrito, no caso, o autor. É com esta concepção que trabalhamos no presente estudo.

Na abordagem discursiva, ao contrário do que ocorre na concepção estruturalista, o leitor assume centralidade, visto que, para o ato de ler, leva uma bagagem com sentidos construídos socioculturalmente e, portanto, perpassados por dada ideologia. O mesmo ocorre com o autor, quando escreve o texto. As ideologias de um e outro, assim, marcam profundamente os atos de escrever e de ler. Por isso, do mesmo modo que a escrita, a leitura, nesta concepção, também é produção de sentido guiada por uma formação ideológica.

\section{Leitura como concepção dialógica}

A concepção discursiva de linguagem destacada por Zappone (apud SCHWARTZ, 2006) ancora-se em Bakhtin (2011), que delineia duas categorias marcantes nas relações verbais: o diálogo e os sentidos, um diálogo que toma forma entre os sujeitos, por meio da linguagem e da interação verbal, sendo esta responsável pela constituição do processo de produção de sentidos, que se dá nas trocas, nas perguntas e nas respostas. 
Trata-se, portanto, de uma abordagem essencialmente ativa, em que os sentidos são constituídos na relação entre o eu e o outro, por meio de enunciados que atuam como discursos nas relações verbais, em situações concretas de comunicação. Desse modo, o sujeito, para Bakhtin (2003, p. 348), não é um ser monológico, uma vez que

a vida é dialógica por natureza. Viver significa participar do diálogo: interrogar, ouvir, responder, concordar etc. Nesse diálogo o homem participa inteiro e com toda a vida: com os olhos, os lábios, as mãos, a alma, o espírito, todo o corpo, os atos. Aplica-se totalmente na palavra, e essa palavra entra no tecido dialógico da vida humana.

É na trama das relações de troca, conforme Côco (2014, p. 24), que "as palavras ganham sentidos no movimento de compreensão do discurso" e no encontro dialógico de duas ou mais consciências. Certeau (1994), por sua vez, dirá que os discursos se cruzam e se entrecruzam, sendo todo enunciado um elo na cadeia comunicativa e discursiva entre os sujeitos envolvidos (BAKHTIN, 2003).

Os discursos, nessa perspectiva, tornam-se palco de encontro com opiniões de interlocutores, de efeito imediato ou retardado. Orais ou escritos, constituem seus sentidos nas diversas atividades humanas, mediados pela linguagem, pelas interações verbais e sociais, gerando atitudes responsivas. Por isso, a relação é sempre dialógica.

A própria compreensão é dialógica, de modo que, cedo ou tarde, o que foi ouvido ativamente responde, nos discursos subsequentes ou no comportamento com o outro, em uma constante interação verbal ou social, porque "a língua vive e evolui historicamente na comunicação verbal concreta" (BAKHTIN, 1999, p. 128) e o seu emprego se efetua em forma de enunciados também concretos, proferidos pelos integrantes desse ou daquele campo de atividade humana.

Se a língua é viva e ininterrupta, a noção de sujeito não pode ser passiva, pois ele não age de maneira solitária, individual. Embora o consumo de produtos seja supostamente passivo, para Certeau (1994), as táticas são lógicas da ação de homens e mulheres, nas quais se fundam discursos e operações astuciosas, mediante o que Ihes foi dado. Ler, olhar e escutar são, efetivamente, atitudes intelectuais que, longe de submeter o consumidor a toda poderosa mensagem ideológica ou estética - que supostamente vai modelá-lo - permite, na verdade, a reapropriação, o desvio da sua condição passiva (CHARTIER, 1990).

Assim sendo, podemos compreender que, em Bakhtin, Certeau e Chartier, o sujeito dialoga com o dado e faz do enunciado um palco de encontro e negociações, deslocando-se da condição de ser determinado, ou seja, de objeto, para a de sujeito livre. Desse modo, ouvir, falar, concordar, perguntar e responder são ações por meio das quais o sujeito pode situar-se ante os enunciados. Nesse processo constitutivo da vida, estabelece diálogos e posicionamentos. Estabelece, ainda, a apropriação dos discursos, isto é, a maneira como eles afetam o sujeito e o conduzem a uma nova compreensão de si próprio e do mundo.

Para Bakhtin (2003, p. 323), as relações dialógicas são interações verbais em que "dois enunciados, quaisquer que sejam, se confrontados em um plano de sentido, acabam em relação dialógica". Se é assim, o ato de leitura compreende ler o dito e o não dito, levando-nos sempre de um texto a outro. Sob essa perspectiva, portanto, a leitura é um diálogo que envolve o meio social do sujeito, que, ao realizá-la, estará ampliando experiências e conhecimentos, constituindo-se em uma nova pessoa. 
O leitor ou indivíduo, central nesse processo de constituição e interação, reconstrói, recria os discursos a partir de suas vivências e experiências, inventando novas leituras, com base em um mesmo texto ou em outros textos, nos quais também estão incluídas suas histórias de leituras e as histórias de leituras do texto. Com tal dinâmica, a leitura representa uma arte que não é passividade, pois o leitor insinua as astúcias do prazer e, a partir da reapropriação do texto do outro, vai "à caça" (CERTEAU, 1994). Ali, o que foi apropriado é transportado e se faz plural, transformando a propriedade do outro em lugar tomado de empréstimo por alguns instantes.

Todavia, o leitor não toma o lugar do autor, nem um lugar de autor, mas inventa, a partir de suas leituras, de sua apropriação, outra coisa que não é aquilo que era a intenção do autor (CHARTIER, 1990). Tal assertiva vai ao encontro do argumento de Bakhtin (2011, p. 311): "o acontecimento da vida do texto, a sua verdadeira essência, se move na fronteira de duas consciências, de dois ou mais sujeitos". Chartier (1990) concebe o texto como espaço aberto a múltiplas leituras, assumindo, assim, um novo sentido: aquilo que é real, efetivamente, então, já não é (ou não é apenas); é a própria maneira como o leitor o cria e o inventa na sua historicidade de produção e na intencionalidade de sua escuta, nas quais os sentidos se constituem.

Nesta via, subjaz ao texto uma concepção de leitura que supera a dimensão monológica, passando a uma concepção movimentada por ações que ultrapassam as operações linguísticas, constituindo-se, assim, em um processo interativo e dialógico, que se realiza por meio do encontro das pessoas: autor, leitor e as diversas vozes que pelo texto perpassam, as quais interferem na (re)construção dos sentidos. Trata-se de uma operação ativa, que não somente constitui as pessoas como também dá vida à própria linguagem.

Está claro que, para a compreensão ativa e responsiva, se exige muito mais que o simples conhecimento linguístico. Conforme Geraldi (1997), a leitura se dá no movimento promovido no encontro entre o eu e o outro, para o qual nós, sujeitos, jamais vamos de mãos vazias e do qual jamais saímos ilesos. Portanto, são vários os aspectos considerados nesta concepção: o suporte, a forma, a estrutura, ou seja, a leitura se processa por diferentes fios, nos quais são construídos, dialógica e discursivamente, os diferentes sentidos.

As pesquisas sustentadas nesta concepção de leitura, de acordo com Zappone (2001) e Schwartz (2006), afinam-se com a linha discursiva, partindo do princípio de que ler é produzir sentidos. A leitura implica um processo discursivo no qual leitor e autor atuam para isso. Para as autoras, um trabalho de leitura no contexto escolar que se baseie em tais princípios amplia o acesso da criança ao conhecimento diferenciado, além de aproximá-la da multiciplicidade de gêneros textuais. Ademais, proporciona um ambiente de aprendizagem que lhe permite restabelecer os sentidos produzidos na leitura.

\section{Procedimentos metodológicos}

Para compreender as concepções de leitura legitimadas pelo Pnaic, empreendemos um estudo documental de abordagem qualitativa, analisando os 35 cadernos formativos de Língua Portuguesa do Pacto. Os cadernos abordam temáticas diversas sobre a alfabetização e foram utilizados pelos envolvidos na formação do Pacto (formadores das universidades responsáveis por operacionalizar o processo formativo, orientadores de estudo e professores alfabetizadores), com a finalidade de refletir sobre as práticas de ensino de leitura e de escrita desenvolvidas no ciclo de alfabetização. 
A análise das concepções de leitura trazidas pelo Pnaic foi realizada a partir de Bakhtin (1999, 2003) e de autores que com ele dialogam, para os quais, como visto, a noção de língua e de linguagem está ligada à concepção de dialogia e polifonia e a leitura constitui-se em um processo discursivo, em que não apenas o autor produz sentido, mas também o leitor, instaurando-o nas condições em que os textos são produzidos, e não somente pairados à intenção de quem os produziu.

Assim, no estudo aqui relatado, tais materiais foram considerados instâncias de interação verbal entre os diferentes sujeitos que participaram da formação. Seus textos, portanto, são entendidos como loci dialógicos que possibilitaram aos sujeitos se apropriar das concepções e práticas consideradas adequadas para orientar a formação e sinalizadas como significativas para o trabalho de leitura na fase da alfabetização.

\section{Resultados \& discussão}

\section{Caracterização dos cadernos do Pnaic}

Os cadernos formativos do Pnaic configuram uma produção constituída por meio de discursos diversos, por onde vários passantes se entrecruzaram (CERTEAU, 1994). Como atividades, trazem varal de textos; preenchimento com letras; quebra-cabeças, dominó, árvore e sorvete com letras. Além disso, utilizam em suas páginas imagens tais como lápis, caderno, caderneta, ampulheta, sinais de interrogação e exclamação, costumeiramente usadas no ciclo de alfabetização.

Tais cadernos podem ser vistos como um conjunto de textos destinados a um público específico, a saber, os envolvidos na formação continuada do Pnaic, sendo documentos constituídos por sujeitos representantes de uma instância governamental (estadual ou municipal), em prol de uma política educacional cujo fim é alfabetizar plenamente todas as crianças até o fim do $3^{\circ}$ ano do ciclo de alfabetização.

Os materiais revelam-se "um produto da sociedade que o fabricou, segundo as relações de forças que aí detinham poder" (LE GOFF, 1996, p. 545). Além disso, os discursos que atravessaram essa dinâmica de trabalho foram relevantes e, dentro da concepção dialógica, no processo de formação visando ao ensino da leitura como produção do conhecimento, foram (re)criados, constituindo-se em textos.

A seção "Compartilhando" de cada caderno destaca os direitos de aprendizagem, que indicam o que as crianças têm o direito de aprender e o que o professor tem como dever ensinar a cada ano do ciclo de alfabetização. Especificamente em Língua Portuguesa, no eixo "Leitura", tais direitos apontam que o aluno poderá "participar de situações de leitura/escuta e produção oral e escrita de textos destinados à reflexão e discussão acerca de temas sociais relevantes (notícias, reportagens, artigos de opinião, cartas de leitores, debates, documentário" (BRASIL, 2012e, p. 30).

O Quadro 1 indica os 19 direitos de aprendizagem em Língua Portuguesa, que são os mesmos para cada ano do ciclo de alfabetização. Ao longo de cada ano, todavia, tais direitos devem ser trabalhados em diferentes níveis de profundidade, a saber: "Introduzir" (I), "Aprofundar" (A) e "Consolidar" (C). 
QUADRO 1 - DIREITOS DE APRENDIZAGEM EM LÍNGUA PORTUGUESA - EIXO LEITURA

\begin{tabular}{|c|c|c|c|}
\hline Direitos de aprendizagem & Ano 1 & Ano 2 & Ano 3 \\
\hline Ler textos não verbais em diferentes suportes & I/A & $\mathrm{A} / \mathrm{C}$ & $\mathrm{A} / \mathrm{C}$ \\
\hline $\begin{array}{l}\text { Ler textos (poemas, canções, tirinhas, textos de tradição oral, } \\
\text { dentre outros) com autonomia }\end{array}$ & I/A & $A / C$ & C \\
\hline $\begin{array}{l}\text { Compreender textos lidos por outras pessoas, de diferentes } \\
\text { gêneros e com diferentes propósitos }\end{array}$ & I/A & $A / C$ & $A / C$ \\
\hline $\begin{array}{l}\text { Antecipar sentidos e ativar conhecimentos prévios relativos aos } \\
\text { textos a serem lidos pelo professor ou pelas crianças }\end{array}$ & I/A & $\mathrm{A} / \mathrm{C}$ & $A / C$ \\
\hline $\begin{array}{l}\text { Reconhecer finalidades de textos lidos pelo professor ou pelas } \\
\text { crianças }\end{array}$ & I/C & $A / C$ & $\mathrm{~A} / \mathrm{C}$ \\
\hline Ler com fluência, em voz alta, em diferentes situações & I & A & $\mathrm{C}$ \\
\hline $\begin{array}{l}\text { Localizar informações explícitas em textos de diferentes gêneros, } \\
\text { temáticas, lidos pelo professor ou outro leitor experiente }\end{array}$ & I/A & $A / C$ & C \\
\hline $\begin{array}{l}\text { Localizar informações em textos de diferentes gêneros, temática, } \\
\text { lidos com autonomia }\end{array}$ & I & $\mathrm{A} / \mathrm{C}$ & $A / C$ \\
\hline $\begin{array}{l}\text { Realizar inferências em textos de diferentes gêneros e temáticas, } \\
\text { lidos pelo professor ou outro leitor experiente }\end{array}$ & I/A & $A / C$ & $A / C$ \\
\hline $\begin{array}{l}\text { Realizar inferências em textos de diferentes gêneros e temáticas, } \\
\text { lidos com autonomia }\end{array}$ & I & I/A & $A / C$ \\
\hline $\begin{array}{l}\text { Estabelecer relações lógicas entre partes de textos diferentes } \\
\text { gêneros e temáticas, lidas pelo professor ou outro leitor experiente }\end{array}$ & I/A & $\mathrm{A} / \mathrm{C}$ & $A / C$ \\
\hline $\begin{array}{l}\text { Estabelecer relações lógicas entre partes de textos, diferentes } \\
\text { gêneros e temáticas, lidos com autonomia }\end{array}$ & I & A & $\mathrm{A} / \mathrm{C}$ \\
\hline $\begin{array}{l}\text { Apreender assuntos/temas tratados em textos, diferentes gêneros, } \\
\text { lidos pelo professor ou outro leitor experiente }\end{array}$ & I/A & $\mathrm{A} / \mathrm{C}$ & $\mathrm{C}$ \\
\hline $\begin{array}{l}\text { Apreender assuntos/temas tratados em diferentes gêneros, lidos } \\
\text { com autonomia }\end{array}$ & I & A & $A / C$ \\
\hline $\begin{array}{l}\text { Interpretar frases e expressões em textos de diferentes gêneros e } \\
\text { temáticas, lidos pelo professor ou outro leitor experiente }\end{array}$ & I/A & $\mathrm{A} / \mathrm{C}$ & $A / C$ \\
\hline $\begin{array}{l}\text { Interpretar frases e expressões em textos de diferentes gêneros e } \\
\text { temáticas, lidos com autonomia }\end{array}$ & I/A & $\mathrm{A} / \mathrm{C}$ & $A / C$ \\
\hline Estabelecer relação de intertextualidade entre textos & । & $\mathrm{I} / \mathrm{C}$ & $\mathrm{C}$ \\
\hline Relacionar textos verbais e não verbais, construindo sentidos & I/A & $\mathrm{A} / \mathrm{C}$ & $A / C$ \\
\hline $\begin{array}{l}\text { Saber procurar no dicionário os significados das palavras e a } \\
\text { acepção mais adequada ao contexto de uso }\end{array}$ & - & I & A \\
\hline
\end{tabular}

Fonte: Caderno da Unidade 1, Ano 1 - Língua Portuguesa (BRASIL, 2012e, p. 33).

Os direitos de aprendizagem constituem, na sua maioria, um conjunto de estratégias que devem ser desenvolvidas durante todo o processo de escolarização, a partir da Educação Básica, conforme propostos, visando desde cedo, ao contato dos alunos com os gêneros textuais, para que possam desenvolver habilidades e competências de leitura e de escrita até o fim do terceiro ano do Ensino Fundamental. 
A partir do Quadro 1, observamos que os direitos de aprendizagem para o ensino de leitura são sustentados ora em uma abordagem conteudista - por exemplo, "localizar informações explícitas ou implícitas em textos de diferentes gêneros e temáticas lidos pelo professor ou outro leitor mais experiente", ora em uma abordagem mais cognitivista, "como antecipar sentidos e conhecimentos prévios relativos aos textos lidos pelo professor ou pelas crianças". Analisamos, que não se trata de uma concepção de leitura resumida à mera decodificação, mas que também não se estende a atividades que estabelecem a leitura para além de uma dimensão interacional.

A leitura na dimensão interacional, mesmo que seja articulada pelo professor no engajamento de estratégias para as quais as crianças recorrerão às informações já apreendidas. No nosso entendimento, não se trata de um trabalho de leitura recomendado para a sala de aula, uma vez que concepções de leitura que se processam nessa abordagem, embora corroborem para a formação de leitores, resumem-se numa compreensão leitora. Daí, concordamos com Orlandi (2001, p. 26), um modo de leitura que não permite escutar outros sentidos que estão naquele acontecimento.

\section{A interação social como concepção-guia do Pnaic para o trabalho de leitura na alfabetização}

Para que a alfabetização das crianças seja efetivada, o Pnaic ressalta que, "no mínimo, os alfabetizadores precisam ter domínio dos conhecimentos necessários ao desenvolvimento do ensino da leitura e da escrita na perspectiva do letramento" (BRASIL, 2012b, p. 12, grifo nosso). O letramento se refere à abordagem de leitura em que o texto é locus de interação social, alcançando o que nele está implícito, sem haver, no entanto, produção de sentidos, objetivo que, na visão de Schwartz (2006) e Zappone (2001), devem ter a leitura e a alfabetização.

À luz da análise, os cadernos do Pnaic apontam o letramento como base teórica para a sustentação das práticas de leitura na fase dos anos iniciais do Ensino Fundamental, conforme encontrado no caderno de "Apresentação": "nos cinco primeiros anos do Ensino Fundamental temos como tarefa básica ampliar o universo de referências culturais das crianças, bem como contribuir para ampliar $e$ aprofundar suas práticas de letramento" (BRASIL, 2012b, grifo nosso).

A confirmação pela perspectiva teórica do letramento no material do Pnaic também fica constatada na relação de objetivos propostos em alguns cadernos, nos quais está a afirmação de que se faz necessário "entender a concepção de alfabetização na perspectiva do letramento" (BRASIL, 2012a, e, f, p. 5, grifo nosso) para o trabalho com a leitura. Os objetivos são assim expressos: "aprofundar conhecimentos sobre a concepção de alfabetização na perspectiva do letramento; planejar o ensino na alfabetização, analisando e criando propostas de organização de rotinas de alfabetização na perspectiva do letramento" (BRASIL, 2012b, p. 5, grifos nossos).

O termo letramento aparece, ainda, na relação dos textos sugeridos para o estudo dirigido dos cadernos do Pnaic, como ocorre no texto n 4, "Integração de crianças de 6 anos ao Ensino Fundamental", de Silviane Bonaccorsi Barbato (BRASIL, 2012d, p. 43), no qual a autora explicita que conceitos fundamentais, como alfabetização e letramento, são mobilizados de modo articulado às reflexões sobre o desenvolvimento infantil e suas relações com a cultura.

Conforme identificado em documentos e nos materiais escritos do Pacto, o letramento é concepção preferencial do MEC para a prática do ensino da leitura e da escrita também nas demais turmas da Educação Básica e para outros programas instituídos 
Souza (2014) assevera que tal concepção carregaria em si um devir correspondente à finalidade posta e almejada pelos organizadores e produtores do Pnaic. Nessa direção, ainda que o Pacto dê a liberdade para o professor selecionar materiais, acaba direcionando esse processo a partir de tal abordagem. Isso fica claro quando analisamos o trecho a seguir: "[...] considerando a concepção de alfabetização defendida anteriormente [o letramento], também se constituem como recursos da formação outros materiais a serem selecionados pelos próprios professores alfabetizadores, que também são importantes no cotidiano da escola" (BRASIL, 2012g, p. 36, grifo nosso).

Assim, nosso entendimento é de que o letramento, talvez, seja a única concepção de leitura articulada na formação do Pacto. Todavia, compreendemos que pautar as discussões e debates apenas em uma perspectiva impossibilita o professor de conhecer ou ter contato com outras bases teóricas. Dificulta, por consequência, que ele compreenda a concepção de alfabetização que vem sustentando suas práticas de leitura e de escrita.

No entanto, é importante ressaltar que a perspectiva teórica do letramento que guia a proposta de trabalho de leitura e de escrita do Pnaic concretiza-se com a adoção de pressupostos metodológicos de abordagens como o interacionismo, a fim de ampliar os conhecimentos e o aprofundamento do trabalho com os diversos gêneros discursivos, e do construtivismo, para a apropriação do sistema de escrita alfabética.

\section{Análise das atividades e estratégias}

É importante descrever as atividades e estratégias propostas pelo Pacto para a mobilização dos momentos de leitura e de reflexão dos professores alfabetizadores, pois, certamente, conforme foram sendo implementadas, reverteram-se em ações didáticas pelos professores cursistas.

Os textos sugeridos nos cadernos do Pacto para a ação formativa foram distribuídos por meio de seções específicas, para facilitar o manuseio e a orientação de leitura dos professores cursistas durante a formação. A fim de demonstrarmos a finalidade e em qual seção específica do material foram disponibilizados os textos sugeridos para os momentos de leitura, realizamos um levantamento e identificamos que:

a) seção "Iniciando a conversa" compõe-se de 32 textos, que tiveram a intenção de apresentar um resumo, as temáticas e os objetivos de cada unidade;

b) a seção "Aprofundando o tema" possui um total de 81 textos, com o objetivo de promover, nos encontros presenciais, a leitura e o estudo dirigido em relação às temáticas propostas para cada unidade;

c) a seção "Leitura compartilhada" constitui-se de 164 textos, que objetivam levar informações complementares ao cursistas, entre elas, a leitura deleite;

d) a seção "Aprendendo mais" possui 162 textos, que constituem indicações e sugestões que levam os professores alfabetizadores a uma leitura suplementar, na qual poderão buscar informações ou pretextos.

Nos 439 textos presentes nas seções descritas, verificamos quatro tipos de leituras mais recorrentes nos cadernos de Língua Portuguesa. Constamos 196 ocorrências que correspondem à leitura como busca de informação, com o objetivo de levar informações complementares aos cursistas; na sequência, 81 ocorrências que correspondem à leitura para estudo do texto, tendo como finalidade aprofundar o tema de cada unidade; outras 81 ocorrências correspondem à leitura como pretexto para outras atividades; por último, 81 ocorrências correspondem à leitura fruição, tendo como objetivo levar um texto descontraído aos leitores e ouvintes. Portanto, esses são os quatro tipos de leitura mais recorrentes na proposta de ação formativa do Pnaic, os quais exemplificam alternativas de entrada do texto no contexto do Pacto. Nesse processo, a interação foi uma intenção marcante, a fim de que o leitor estabelecesse sentidos com o solicitado nos enunciados das atividades e construísse um objetivo e o novo a partir do contato com a leitura com os textos. 
Conforme Zappone (2001), quando isso é alcançado, há uma melhor intenção com o texto, pois compreender a intenção do outro é uma forma de diálogo. Quando dialogamos com o sentido que o outro deixou, fazemos corresponder à sua compreensão uma série de vivências e experiências nossas. Se entendermos o outro por meio dos acontecimentos interativos e do diálogo, a compreensão já não será mera decodificação e a reflexão começa se fazer presente (GERALDI, 1997).

Constatamos, também, que os objetivos propostos pelo Pacto conseguiram mobilizar a interação do leitor com o objeto texto e a interação do leitor-texto-outro. As situações de leitura planejadas se centraram ora em momentos de leitura individuais; ora em momentos coletivos, em pequenos e grandes grupos, de forma compartilhada ou silenciosa; ora de forma oralizada. Por outro lado, concordamos que, embora essas leituras tenham se constituído como fios condutores da reflexão (GERALDI, 1997), também exigiram dos orientadores de estudo, diante do "mundo dado", a inspiração para promover o diálogo, pois "o novo não está no que é dito, mas no acontecimento de seu retorno e também no retorno" (FOUCAULT apud GERALDI, 1997, p. 185).

Além disso, notamos que as atividades e as estratégias sugeridas para os momentos de leitura foram, a cada passo, ditadas pelos objetivos pretendidos, recorrentes pelo uso do verbo "ler", sendo responsáveis por despertar nos professores aquilo que realmente interessou para a atribuição de sentidos. A Tabela 1 apresenta os objetivos propostos para o trabalho de leitura com os professores alfabetizadores na ação formativa e oferece uma visão mais ampliada em relação a eles.

TABELA 1 - OBJETIVOS PROPOSTOS PARA OS MOMENTOS DE LEITURA

\begin{tabular}{lcc}
\hline \multicolumn{1}{c}{ Atividades/finalidades } & $\begin{array}{c}\text { Unidades em que } \\
\text { foram identificadas }\end{array}$ & $\begin{array}{c}\mathbf{N}^{\circ} \text { de } \\
\text { ocorrências }\end{array}$ \\
\hline 1. Ler leitura deleite & Todas & 69 \\
2. Ler o texto & Todas & 49 \\
3. Ler a seção & Todas & 32 \\
4. Ler em pequenos grupos & $3,5,6,7,8$ & 13 \\
5. Ler um dos textos sugeridos ou da seção & $1,2,3,4,5,6$ & 9 \\
6. Ler um relato/depoimento/experiência & $4,5,6,7,8$ & 8 \\
7. Ler e discutir & $3,4,5,6,7$ & 7 \\
8. Ler o quadro de direitos de aprendizagem & $1,4,5$ & 6 \\
9. Ler de forma/modo compartilhado & $3,4,6$ & 4 \\
10. Fazer ou realizar leitura compartilhada & $3,4,5$ & 4 \\
11. Ler coletivamente & $1,4,7,8$ & 4 \\
12. Ler resenhas & 7 & 3 \\
13. Ler individualmente & 7 & 2 \\
14. Ler em grupo & 4,5 & 2 \\
15. Ler em grande grupo & 8 & 2 \\
16. Ler e elaborar & 6 & 1 \\
17. Ler sequência didática & 6 & 1 \\
18. Reler o texto & Total de ocorrências & $\mathbf{2 1 7}$ \\
\hline & $\mathbf{2 1 4}$ \\
\hline
\end{tabular}

Fonte: elaborada a partir dos Cadernos Pnaic - Língua Portuguesa. 
Como observado na tabela, os 18 objetivos que mobilizaram os momentos de leitura tiveram como principal foco de promover a interação dos cursistas com o objeto (texto), por meio do uso do verbo "ler" (presente em 16 objetivos); "reler" (1) e "fazer ou realizar leitura" (1). Dos 18 objetivos elencados, em 15, o comando é dado pelo verbo "ler". Apenas os objetivos 16, 17 e 18 não retomam a ação por meio deste verbo. Entretanto, apesar de não haver essa mesma repetição em todos os objetivos dos enunciados analisados, o efeito transmitido é o mesmo.

Inferimos que a leitura mobilizada por meio dos objetivos apontados nos enunciados, até podem ter possibilitado no leitor uma interação e a compreensão da intencionalidade de quem os elaborou. Porém, concordamos com Orlandi (2001, p. 30), [...] os sentidos não estão só nas palavras, nos textos, mas na relação com a exterioridade, nas condições em que eles são produzidos, e não dependem só das intenções dos sujeitos".

A partir disso, reiteramos que se a articulação do mediador na ação formativa, não ultrapassou o comando dos enunciados, para além do sugerido no material; visto que, concordamos com Geraldi (1997,p.168), que "a construção do leitor opera a partir do trabalho do outro", a transformação, talvez, não tenha sido fruto de reflexão para que se materializasse o novo nas práticas docentes dos professores com os alunos. Ou seja, caso não tenham sido articuladas as táticas para operações astuciosas, conforme nos fala (CERTEAU, 1994), provocando nos professores, e estes nos alunos, a ação para além do ler, o movimento não afetou os sujeitos e os sentidos.

Portanto, compreendemos que a figura do orientador de estudo foi de grande relevância para ação formativa, pois, como interlocutor, pode dar vida e fazer as provocações necessárias para que essa relação do leitor com o sentido se materializasse para além da individualidade dos sujeitos em formação. Nessa perspectiva, concordamos com Zappone (2001)e Orlandi (2001) se não houve a interferência do articulador, esse leitor/cursista não se constituiu, em instância comunicativa no ato de leitura e não houve uma leitura discursiva.

Também analisamos as atividades sugeridas para os momentos de leitura pelos cadernos de formação do Pnaic. Observamos que os enunciados traziam um comando orientador, indicando se a atividade era de caráter individual ou coletivo (Quadros 2, 3 e 4).

\section{QUADRO 2 - EXEMPLO DE ATIVIDADE CENTRADA NA INTERAÇÃO AUTOR-TEXTO}

Ler o texto 2 (Concepções de alfabetização: o que ensinar no ciclo de alfabetização?): resgatar as experiências vivenciadas como estudantes e professores, identificando as concepções de ensino subjacentes às vivências.

Fonte: Unidade 1, Ano 1 (BRASIL, 2012e, p. 46).

\section{QUADRO 3 - EXEMPLO DE ATIVIDADE CENTRADA NA INTERAÇÃO LEITOR-TEXTO-OUTRO}

Ler um dos textos sugeridos na seção "Sugestões de leitura" e elaborar uma questão a ser discutida com o grupo (decidir coletivamente qual texto será discutido).

Fonte: Unidade 8, Ano 2 (BRASIL, 2012h, p. 47).

QUADRO 4 - EXEMPLO DE ATIVIDADE CENTRADA NA INTERAÇÃO LEITOR-TEXTO-OUTRO

Ler em grupo os quadros de "Direitos de aprendizagem - em Língua Portuguesa"; analisar o instrumento de avaliação disponível no Portal, para identificar quais direitos de aprendizagem estão contemplados no instrumento. 
A partir dos quadros, depreendemos que, tal como propostos os enunciados, em função do recorrente uso do verbo "ler", a reação ou o efeito inicial provocado no leitor pode ter sido o mesmo que os velhos e mecânicos comandos de leitura já impactaram nos leitores em tempos anteriores. Ou mesmo, nem despertaram o leitor para controlar o que foi sendo lido ou the permitiram tomar decisões a partir deste. Diante disso, inferimos que não visualizamos um movimento que contribuísse para a produção da diversidade de sentidos. Isso porque, conforme se nota nos quadros, as atividades trazem comandos determinantes os quais se resumem numa relação tríade entre autor-texto-leitor. Em outras palavras, são provocações repetidas por meio de um encontro do leitor com o texto, a partir de objetivos de leitura propostos por um outro sujeito e dos conhecimentos prévios do leitor, que resultam em leitura e compreensão do texto, conforme nos fala Gontijo e Schwartz (2009, p.93), e defendem que:

[...] a compreensão de um texto não se encerra nele mesmo, nem nas capacidades cognitivas do leitor". Assim, a leitura envolve não apenas a busca de informações explícitas no texto ou habilidades cognitivas do leitor, mas, sobretudo, os sentidos atribuídos à leitura a partir da bagagem cultural, dos conhecimentos e experiências do leitor. Portanto, o diálogo é o que possibilita a produção de sentidos (apud, COSTA, 2017, p.154-155).

A partir do levantamento das atividades de leitura sugeridas nos planejamentos para ação formativa, notamos que estas apresentam variação quanto ao foco, ora centrado no leitor com o texto, ora no leitor-texto-outro (Tabela 2).

TABELA 2 - VARIAÇÃO DO FOCO DAS ATIVIDADES DE LEITURA SUGERIDAS PELO PNAIC

\begin{tabular}{ccc}
\hline $\begin{array}{c}\text { Unidades analisadas } \\
\text { nos Anos 1, 2, 3 e } \\
\text { Educação do campo }\end{array}$ & $\begin{array}{c}\text { Atividades de leitura } \\
\text { centradas na interação } \\
\text { leitor-texto }\end{array}$ & $\begin{array}{c}\text { Atividades de leitura } \\
\text { centradas na interação } \\
\text { leitor-texto-outro }\end{array}$ \\
\hline Unidade 1 & 7 & 26 \\
Unidade 2 & 10 & 22 \\
Unidade 3 & 4 & 19 \\
Unidade 4 & 6 & 30 \\
Unidade 5 & 8 & 25 \\
Unidade 6 & 6 & 33 \\
Unidade 7 & 8 & 30 \\
Unidade 8 & 5 & 35 \\
Total & $\mathbf{5 4}$ & $\mathbf{2 2 0}$ \\
\hline
\end{tabular}

Fonte: elaborada a partir dos Cadernos Pnaic - Língua Portuguesa.

Portanto, entre as 274 atividades propostas para a mobilização do trabalho de leitura com o grupo de cursistas, percebemos que, inicialmente, o foco ficou centrado no texto, no momento da leitura individual, em que o leitor recuperou seu sentido, por meio do comando dado para a leitura (ex.: "leia o texto", "leia um dos textos sugeridos e faça uma pergunta", "leia a seção 'Iniciando a conversa'" etc.). Na sequência, esses sentidos, somados aos outros, vividos em particular pelos demais cursistas, constituíram-se por meio da interação entre o leitor-texto-outro, com comandos tais como "realize a leitura compartilhada", "discuta em grande grupo", "leia o texto em grupo". 
Desse modo, aferimos que $20 \%$ do total geral (54) das atividades de leitura sugeridas para a ação formativa do Pacto puseram foco na interação texto-leitor, momento da leitura individual do leitor com o texto. Os outros $80 \%$ das atividades (220) focaram na interação leitor-texto-autor, quando os leitores interagiram com o autor ou com os demais colegas de curso, a partir do comando dado pelo orientador de estudo, a fim de dialogarem com as pistas deixadas pelo autor.

Diante disso, constatamos que, para o trabalho de leitura, o Pacto apontou modelos com focos distintos. Ora este estava centrado no texto como forma de interação (modelos ascendentes de leitura, que tomam como primeira referência o todo para, então, chegar às partes), ora no leitor, por meio das teorias cognitivas (modelos descendentes de leitura, que fazem o movimento inverso, tomando, primeiro, as partes para alcançar o todo). Havia, principalmente, o interesse na interação leitor-texto (modelos interacionais), caracterizada por Zappone (2001) como uma forma de interação que influenciou e ainda influencia o trabalho de leitura na atualidade.

Sobre o conjunto de atividades apresentadas na Tabela 2, concluímos que a maior parte levou o leitor a recorrer ao seu conhecimento prévio, linguístico, textual, abarcando, também, seu conhecimento de mundo, possibilitando inferências, elaboração de hipóteses. Em outras palavras, observamos um modelo de leitura que permitiu a interação entre os sujeitos e o texto. Nesse caso, esse leitor/cursista, ao recorrer aos seus conhecimentos prévios e de mundo, conseguiu estabelecer uma compreensão mais completa e efetiva dos textos, indo além da interação.

Portanto, da análise, depreendemos que a concepção de leitura legitimada pelo Pacto para o ensino da leitura não se trata de mero código, uma compreensão mecânica ou de decodificação. O texto não é visto apenas como instrumento de comunicação, mas é o objeto de interação dos sujeitos sociais e o professor, que, nesse processo, é considerado muito relevante. Isso porque,

se entendermos a linguagem como mero código, e a compreensão como decodificação mecânica, a reflexão pode ser dispensada; se a entendermos como uma sistematização aberta de recursos expressivos cuja concretude significativa se dá na singularidade dos acontecimentos interativos, a compreensão já não é mera decodificação e a reflexão sobre os próprios recursos utilizados é uma constante em cada processo (GERALDI, 1997, p. 18).

Assim sendo, constatamos que o Pacto concebe o texto para o ensino da leitura como objeto e ferramenta de interação entre os sujeitos falantes. Desse modo, não é visto como representação mental ou como um produto lógico do pensamento. Compreendemos que subjaz a esse conceito de texto e de leitura uma concepção que se distancia da leitura como mera atividade de extração de ideias do autor. Conforme Zappone (2001, p. 55) neste caso, o leitor está em "[...] posição de um sujeito no processo de significado, e não de um mero receptor de ideias vinculadas pelo texto e pelo autor".

Em todos os cadernos analisados, observamos que o trabalho com a leitura é pontuado como primordial para o processo ensino-aprendizagem, tomando como fundamental um trabalho com os gêneros textuais de modo que os alunos saibam fazer o uso social da escrita e da leitura:

Em todos os anos de escolarização, as crianças devem ser convidadas a ler, produzir e refletir sobre textos que circulem em diferentes esferas sociais de interlocução, mas alguns podem ser considerados prioritários, como os gêneros da esfera literária; esfera acadêmica/escolar e esfera midiática, destinada a discutir temas sociais relevantes (BRASIL, 2012, ano 3, unidade 1, p. 30). 
Mediante ao exposto, notamos a preocupação dos elaboradores com a vinculação do professor ao ensino da leitura a partir de um trabalho que envolva os gêneros textuais, porém, ao nosso ver resumem-se num trabalho que toma como base a organização estrutural e a composição do próprio texto. Essa sistemática, inclusive, foi reforçada como uma atividade em que os professores alfabetizadores apreciaram no estudo dos textos da ação formativa, diferentes relatos de experiências com práticas docentes envolvendo o uso de diferentes gêneros textuais em sala de aula implementados em diferentes regiões brasileiras. Inferimos, entretanto, que um trabalho dessa natureza, em que a leitura se centra no próprio texto, deixa de possibilitar uma leitura discursiva, a qual, nos fala Orlandi (2001), de propor escutas e efeitos de um saber que não se aprende, que não se ensina, mas que produziu sentidos no leitor.

Mediante a análise, consideramos que o Pnaic compreende que à escola cabe o papel de corresponsável a promover uma educação de qualidade e de dar o acesso à cultura de leitura e de escrita às crianças, como prática social. Tem na leitura uma atividade interativa, pautada em atividades associadas aos termos letramento e "alfabetizar letrando", no contato com os gêneros textuais e usos sociais da leitura. Ou seja, são atividades que tendem a explorar os elementos presentes na superfície textual e na sua forma organizacional, que requerem a mobilização de um conjunto de saberes no interior do evento comunicativo, com destaque apenas aos gêneros e tipologias textuais.

Reiterando, no Pnaic, texto é lugar de interação a partir das marcas dadas pelos enunciados e pelo professor, associadas aos conhecimentos acumulados pelos cursistas, na ação formativa, e/ou pelos estudantes, nas salas de aula. Daí, subentendemos que a figura do docente no contexto do programa é de grande relevância, "[...] na medida em que ajuda os alunos a reconhecerem as relações entre os textos e os explora, evidenciando os pontos de contato com outros textos que circulam em variados grupos sociais" (BRASIL, 2012, p. 18). Além disso, o professor encoraja os alunos a se aproximarem de outras potencialidades, cumprindo o pressuposto de que é dever da escola garantir situações favoráveis de aproximação entre a cultura escolar e a cultura própria de outras esferas de interação social.

\section{Considerações Finais}

Este estudo buscou compreender as concepções de leitura balizadas pelo Pacto a partir da análise dos documentos usados na formação de professores desse programa. Como vimos, a concepção de alfabetização privilegiada pelo Pnaic para o trabalho de leitura e de escrita se dá na abordagem do letramento. Esta concepção de leitura enfatiza a interação leitor-texto-autor, em que o texto é visto como um lugar de interação, no qual os sujeitos nele ou a partir dele se constituem. Ao trabalho de leitura nesta perspectiva, subjaz a noção de que, ao ler, é mobilizado um conjunto de pistas e estratégias que possibilitam ao leitor apreender o sentido do texto e recuperar o sentido deixado pelo autor. Isso instigou-nos a analisar o modo como esses conceitos são apresentados pelos cadernos, para que, assim, fosse possível apresentar as concepções de linguagem, sujeito e sentidos fundamentados pela formação do Pnaic.

Embora os cadernos usados pela ação formativa do programa tenham enfatizado a importância do trabalho de leitura por meio de práticas que visam à aproximação da criança, desde cedo, com a diversidade textual, ao analisá-los, não vislumbramos práticas discursivas de reflexão sobre o texto e sobre seu contexto histórico-cultural, assim como sobre o contexto dos sujeitos instaurados ou não no texto. Verificamos que o Pnaic se baliza em abordagens, que se resumem nas concepções e modos de conceber a leitura, a saber: a conteudista, relacionada às estruturas textuais; a cognitivista, centrada em estratégias de leitura e no processamento textual e como forma de interação, centrada no leitor/texto para os usos sociais do texto. 
Ao analisarmos as incidências no material da ação formativa, constatamos que o trabalho de leitura é bastante mencionado e destacado pelo programa por meio de uma perspectiva do letramento. Destaque é dado às atividades educativas que tomam como foco um trabalho a partir de uma leitura que tem como ênfase a interação por meio do uso estratégias de leitura, usos sociais da leitura e dos gêneros textuais. Ou seja, um ensino focado para o significado do texto e que não o concebe em sua discursividade. Toma a linguagem ora para um ensino conteudista, ora em uma perspectiva cognitivista, ou para compartilhamento da leitura e interação leitor/texto/autor.

Dessa forma, a proposta para o trabalho de leitura, ao nosso ver, articula concepções de leitura no campo da leitura como prática social, cognitivista e para o próprio texto. Todavia, o discurso que legitima a ação formativa tem como base forte o significado no texto e no autor, tratado como unidade textual, estrutural, semântica e de interação social com um trabalho ainda bastante constituído por sentenças e pelas intenções de quem o elaborou.

Desse modo, percebemos que faltou a legitimação de concepções de leitura que tomam o texto a partir de práticas discursivas, de sentenças como reflexão para encontrar outros sentidos a partir dele. O trabalho de leitura postulado pelo programa ainda é pautado em perspectiva de ensino de leitura que não consegue ultrapassar velhas práticas já utilizadas pelos docentes. A todo tempo, o texto é tomado como o palco de encontro entre o leitor e o autor. Tanto na ação formativa quanto no trabalho proposto para o ensino de leitura com as crianças, frequentemente, os interlocutores são percebidos servindo a uma articulação que se delineia na dimensão de interação e seguir comandos. Durante a formação, a leitura e a articulação ficaram resumidas à figura dos mediadores e dos cursistas e, posteriormente, no trabalho a ser realizado na sala de aula, aos docentes e alunos.

Assim, depreendemos que a proposta de leitura do Pnaic, em uma visão um tanto pragmática, aponta para a melhoria das práticas de leitura e dos docentes, promovendo uma articulação que levou em conta apenas a figura do mediador na ação formativa e a do docente na sala de aula. Muitas outras questões para além do compromisso da escola e do professor, culturais, históricas, econômicas, deixaram de ser alvo de discussão.

Concebemos o processo ensino-aprendizagem em numa perspectiva histórico-cultural e dialógica do conhecimento, em que o sujeito é atravessado pela linguagem e por outros sujeitos discursivos, que se posicionam pela história e que contribuem para produzir sentidos. Logo, os sujeitos são sociais, históricos e ideologicamente afetados pelos demais discursos, e não apenas por práticas docentes que tomam o texto como compreensão da língua ou do autor, sem possibilitar uma atitude responsiva com os outros discursos ali instituídos. Por isso, em programas voltados ao desenvolvimento das práticas de leitura, é preciso haver esforço para superar as lacunas apontadas.

Nos resultados apresentados, há, portanto, um hiato que dificulta ao leitor sair de sua condição de dominado para a condição livre. Em consequência disso, podemos indagar se, no trabalho posteriormente realizado com as crianças, esses professores alfabetizadores conseguiram proporcionar algo neste sentido, objeto que pode ser alvo de investigações futuras. 


\section{Referências}

BAKHTIN, M. Estética da criação verbal. São Paulo: Martins Fontes, 2003.

BAKHTIN, M. Marxismo e filosofia da linguagem: problemas fundamentais do método sociológico na ciência da linguagem. São Paulo: Hucitec, 1999.

BRASIL. A heterogeneidade em sala de aula e os direitos de aprendizagem no ciclo de alfabetização. Ano 2, Unidade 7. Brasília: 2012a.

BRASIL. A organização do planejamento e da rotina no ciclo de alfabetização na perspectiva do letramento. Ano 2, Unidade 2. Brasília: 2012b.

BRASIL. Alfabetização em foco: projetos didáticos e sequências didáticas em diálogo com os diferentes componentes curriculares. Ano 3, Unidade 6. Brasília: 2012c.

BRASIL. Ludicidade na sala de aula. Ano 1, Unidade 4. Brasília: 2012d.

BRASIL. Ministério da Educação. Secretaria da Educação Básica. Diretoria de Apoio à Gestão Educacional. Pacto Nacional Pela Alfabetização na Idade Certa. Currículo na alfabetização: concepções e princípios. Ano 1, Unidade 1. Brasília: 2012e.

BRASIL. Ministério da Educação. Secretaria de Educação Básica. Documento orientador das ações de formação continuada de professores alfabetizadores em 2015.

BRASIL. O último ano do ciclo de alfabetização: consolidação do processo de alfabetização - consolidando os conhecimentos. Ano 3, Unidade 3. Brasília: 2012f.

BRASIL. Pacto Nacional pela Alfabetização na Idade Certa: formação do professor alfabetizador - caderno de apresentação. Brasília: 2012g.

BRASIL. Reflexões sobre a prática do professor no ciclo de alfabetização: progressão e continuidade das aprendizagens para a construção do conhecimento por todas as crianças. Ano 2, Unidade 8. Brasília: $2012 \mathrm{~h}$.

BRASIL. O currículo inclusivo: o direito de ser alfabetizado. Ano 3, Unidade 1. Brasília: 2012j.

CARVAlHO, M. Guia Prático do Alfabetizador. 5 ed. São Paulo: Ática, 2004

CELLARD, A. A análise documental. In: POUPART, J. et al. (Orgs.). A pesquisa qualitativa: enfoques epistemológicos e metodológicos. Petrópolis: Vozes, 2008. p. 295-316.

CERTEAU, M. de. A invenção do cotidiano: artes de fazer. Petrópolis: Vozes, 1994. v. 1.

CHARTIER, R. A história cultural entre práticas e representações. Tradução de Maria Manuela Galhardo. Rio de Janeiro: Bertrand Brasil, 1990.

CÔCO, V. A dimensão formadora das práticas de escritas de professores. Curitiba: CRV, 2014.

COSTA, K. W. C. Cadernos de formação do PNAIC em Língua Portuguesa: concepções de alfabetização e letramento. Tese (Doutorado em Educação) - Programa de Pós-graduação em Educação, Universidade Federal do Espírito Santo, Vitória, 2017.

GERALDI, J. W. Portos de passagem. São Paulo: Martins Fontes, 1997.

GONTIJO, C. M. M. Alfabetização: políticas mundiais e movimentos nacionais. Campinas: Autores Associados, 2014.

GONTIJO, C. M. M. O processo de alfabetização: novas contribuições. São Paulo: Martins Fontes, 2002.

LE GOFF, Jacques. História e memória. 4. ed. Campinas: Unicamp, 1996.

ORLANDI, E. P. Discurso e leitura. 9. ed. Campinas: Cortez, 2012. 
ORLANDI, E. P. Análise de discurso: princípios e procedimentos. 3. ed. Campinas: Pontes, 2001.

SCHWARTZ, C. M. Os sentidos da leitura. In: REUNIÃO ANUAL DA ASSOCIAÇÃO NACIONAL DE PÓSGRADUAÇÃO E PESQUISA EM EDUCAÇÃO, 29., 2006, Caxambu. Anais eletrônicos... Disponível em: <http:// www.anped.org.br/biblioteca/item/os-sentidos-da-leitura>. Acesso em: 22 ago. 2016.

SCHWARTZ, C. M. Os sentidos do texto. Cadernos de Pesquisa em Educação, Universidade Federal do Espírito Santo, Centro de Educação, PPGE, v. 12, n. 24, p. 25-50, 2006.

SOLÉ, I. Estratégias de leitura. 6. ed. Porto Alegre: Artmed, 1998.

SOUZA, E. E. P. A formação continuada de professor alfabetizador nos cadernos do Pacto Nacional pela Alfabetização na Idade Certa - PNAIC. 2014. 358 f. Dissertação (Mestrado em Educação) - Universidade Federal de Santa Catarina, Florianópolis, 2014.

ZAPPONE, M. H. Y. Práticas de leitura na escola. Tese (Doutorado em Teoria Literária) - Instituto de Estudos da Linguagem, Universidade Estadual de Campinas, Campinas, 2001.

Recebido em: 26/10/2019

Aceito em: 05/04/2020 